\title{
Taking a Motivational Interviewing Approach to Prevention Science: Progress and Extensions
}

\author{
Daniel S. Shaw ${ }^{1} \cdot$ Melvin N. Wilson ${ }^{2}$ \\ Accepted: 15 June 2021 / Published online: 25 June 2021 \\ (c) Society for Prevention Research 2021
}

\begin{abstract}
This commentary reviews advances gleaned from the current set of papers to Motivational Interviewing (MI) in prevention science. We begin by acknowledging the pioneering work of Miller and Rollnick to develop the construct of MI, then Dishion's use of MI principles to adapt applications of MI for the field of prevention science. We then highlight some of the contributions provided by the current set of papers and other recent extensions of MI. These novel applications are directed to parents, teachers, and older youth in the service of facilitating behavior change to promote youth development.
\end{abstract}

It is most fitting that Prevention Science brought together innovative and rigorous applications of motivational interviewing (MI) at the current juncture. Since Miller and Rollnick (2002) original development of the construct, there have been numerous applications of MI used with adults and children. The field of prevention science has held a special place for applications of MI because of its inherent emphasis on engaging adults and children in change behaviors prior to the emergence of more serious forms of problem behavior. Reading through the variety of innovative applications of MI in this Special Issue made us appreciate how different silos have been generated for MI applications directed towards parents, teachers, and youth. Applications of MI also have become differentiated by populations of interest (e.g., child disruptive behavior, obesity, perinatal substance use exposure), modalities of dissemination (e.g., individual, group, in-person, virtual remote), and initial point of contact (e.g., health care, school, childcare, home-visiting), making the timing of the Special Issue especially noteworthy.

Operating within traditional silos of prevention science, including parent-, teacher-, and youth-based programs, it is not surprising that the use of MI has been found to be usefully applied across the various contexts. Consistent with the divergent and recent use of MI across multiple contexts, the current set of papers reflect the many substantive (e.g., mechanisms, moderators of treatment response) and

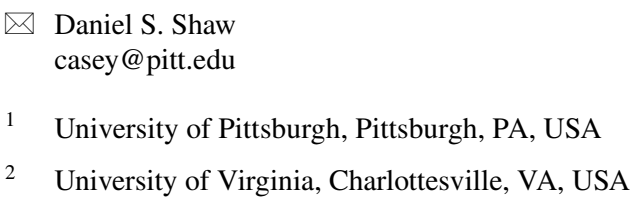

methodological (e.g., measurement, optimizing engagement) holes needed to be filled, and opportunities to utilize MI approaches with new populations, age groups, and modalities of communication.

\section{Contributions of Tom Dishion}

Before discussing the contributions of individual papers, it is important to reflect and acknowledge how the current interest in MI applications within prevention science occurred. Much like how the original work of Bowlby and Ainsworth led to the development of several attachment-based interventions during early childhood (e.g., Dozier's ABC, Cooper's Circle of Security), and the seminal efforts of Patterson (1982) led to the development of many social-learningbased parenting approaches (e.g., parent management training, parent-child interaction therapy, incredible years), it is reasonable to suggest that Tom Dishion played a comparable role in setting the stage for the proliferation of work incorporating MI into prevention science. Dishion translated the internal dissonance created by Miller's and Rollnick's use of MI for adults struggling with substance abuse to parents concerned with the future welfare of their adolescents (Shaw et al., 2018). While it does not appear that every study in the Special Issue was directly influenced by Dishion's use of MI in the Family Check-Up approach (FCU), Tom's insights and influence regarding the significance of MI in family clinical work likely inspired many of the articles in this volume. Thus, in addition to paying homage to Miller and Rollnick for developing the construct of MI, it is also appropriate to 
acknowledge Dishion's considerable impact in adapting MI for use in prevention science.

Moreover, in developing the FCU, Dishion also modeled a culture for researchers to explore new populations, age groups, and contexts for expanding the reach of MI. Thus, while beginning as a program for parents of early adolescents in the middle school context, Dishion was open to broadening the FCU's reach to new age groups, including parents struggling with toddlers' burgeoning autonomy during the terrible twos (Dishion et al., 2008; Shaw et al., 2006). In addition to expanding the age range for deploying the FCU, Dishion appreciated the need to modify how parents of younger children would be "recruited," taking advantage of the existing and national Women, Infants, and Children's (WIC's) Nutritional Supplement program. More recently, further efforts have led to expanding the early childhood version of the FCU to other platforms frequented by parents of young children living in poverty, including primary pediatric care, federally qualified health centers, Early Head Start, and Head Start, as well as family support centers. Similarly, the FCU's initial substantive focus on preventing risky behaviors of adolescence (e.g., substance use, antisocial behavior) has been expanded to include the prevention of depression and suicide risk (Connell et al., 2019), obesity (see Berkel et al., 2021 in current volume), and the promotion of school readiness (Roby et al., 2021). As featured prominently in the Special Issue, Reinke et al. (2008) developed a classroom checkup by applying principles of MI incorporated into the FCU for teacher's management of children in the classroom.

We now offer some comments about how the current set of manuscripts has contributed to the application of MI in prevention science. We review studies based on the application of MI to parents (and in some cases, youth), teachers, and older youth and young adults.

\section{Parenting}

Within the domain of parenting-based applications of MI, Berkel et al. (2021) demonstrated the FCU 4 Health's ability to promote parent's active engagement in intervention and participate in a greater number of follow-up treatment sessions, which is related to the interventionist's MI skills demonstrated in the first session. The Stormshak et al. (2021) paper replicates prior work using the FCU with both parents of adolescents (Connell et al., 2016) and toddlers (Dishion et al., 2008), demonstrating that improvements in both parent and teacher reports of child problem behavior were mediated by improvements in positive parenting. The novelty here is testing the FCU with children transitioning to kindergarten, capitalizing on a developmental transition for children (and parents). The selected age group is consistent with prior trials of the FCU initiated during the turbulent developmental periods of early adolescence and the "terrible twos."
On the near horizon in applying MI approaches with parents is remote delivery of the FCU, already spanning from early childhood to early adolescence. Pioneered by Beth Stormshak (Stormshak et al., 2019) initially for families living in remote rural locations, in the context of the coronavirus pandemic, the online version of the FCU has become invaluable and will continue to provide interventionists and parents with enhanced flexibility for engaging families.

Another innovation to MI in general and FCU in particular has been combining MI applications with other approaches to address the heterogeneity of risk facing families living in poverty. The impetus for combining forces with other intervention models is also based on findings reported on by Pelham et al. (2017). Based on a RCT of WIC families with toddlers followed through age 5 with annual reports of child conduct problems, the FCU showed moderate to high effect sizes for families with additional family and child risks beyond financial stress (e.g., maternal depression, parental antisocial behavior, child protective services). However, effect sizes for WIC families without additional risk factors were minimal. The Family Check-Up is now used as part of a 0 to 3 model with the universal preventive intervention model, video interaction project (VIP). Known as the Smart Beginnings model (Shaw et al., under review), all families receiving public insurance with newborns are offered VIP, with families experiencing additional family or child risk (e.g., maternal depression, family violence, low-social support) that were also offered the FCU. Initial data suggest strong engagement rates that are amplified for higher-risk families offered both VIP and FCU (e.g., high engagement in VIP associated with subsequent high engagement in FCU and engaging in FCU related to subsequent engagement in VIP for previously low VIP engagers; Canfield et al., 2021).

The Small et al. (2021) study also represents an important stepping stone in validating the utility of MI approaches with parents, demonstrating that school personnel could be reliably trained to deliver an MI-based program to support parents. The three studies stretch preexisting boundaries in using MI, pioneering its use with new populations and age periods, as well as making advances in sustainability by utilizing existing school staff.

Another study that sought to extend the traditional reach of family-based applications using MI was a contribution by Sibley et al. (2021). The authors tested the implementation of the well-established Supporting Teens' Autonomy Daily (STAND) program for adolescent youth and their parents at four community mental health clinics that are much like the FCU, incorporating MI and behaviorally based family management practices. As prior trials using STAND previously had been limited to training university-based interventionists, an RCT design was used to compare feasibility, acceptability, and fidelity between STAND and usual care. Findings indicated that community therapists found both 
training and supervision to be acceptable having a lower burden than usual care interventions; however, MI competence and implementation were lower than found in university settings, and content fidelity tended to decrease after initial sessions (e.g., deterioration of weekly review of goals and home practice). Some of the disappointing findings were linked to the poorer resources of community-based clinics, which was reflected in the reduced amount of time available to train and supervise community therapists relative to STAND's typical practices with university-based trainees.

\section{Teachers}

In recent years, a considerable amount of intervention research using parent training and specifically MI-based parenting approaches has been dedicated to examining moderating factors of treatment response (see Shelleby \& Shaw, 2014). It is therefore a welcome and logical development that many of the teacher-based papers in the current volume are focused on factors that could moderate teachers' and children's response to MI-based approaches. Also consistent with research needed to better understand the change process underlying MI, one paper addresses mechanisms by which MI consultations with teachers are associated with their behavior change.

Owens et al. (2021) examined initial individual differences in teachers' perceptions of the importance of the intervention plan and teachers' level of confidence in carrying out the plan as predictors of intervention delivery effectiveness. The authors found that those teachers with high confidence at baseline doubled their use of management strategies by the second intervention session, whereas use of management strategies for those with initially low confidence improved more modestly. As similar results were found for teachers' initial perception of the importance of their plan, additional strategies could be developed to improve uptake for teachers with initial low levels of confidence and/or importance of the intervention.

Thompson et al. (2021) used person-centered methods to examine whether there are students whose daily motivation and readiness for change are influenced by teacher feedback in relation to the impact of self-monitoring and regulation training strategy. Whereas one group of students' daily readiness aligned with teacher agreement on performance ratings, a group of students' daily motivation and readiness for change was adversely influenced by negative teacher feedback on the previous day. The same group of students showed high levels of depression and internalizing symptoms, suggesting that they might benefit by the introduction of teacher-applied MI practices.

Taking a lesson from parenting interventions that have implemented MI strategies prior to the delivery of a parenting intervention to enhance its engagement, Larson et al. (2021) describe a motivational tool to improve motivation for teachers about to receive training in implementing the Good Behavior Game. Implementation of the MI-based program improved both self-efficacy and intentions to implement the Good Behavior Game. Larson and colleagues' findings are consistent with mechanisms underlying teachers' behavior change in prior research.

Pas et al. (2021) also were interested in advancing our knowledge of processes underlying behavior change using MI with teachers. They used sequential analysis to examine how teachers' verbalization of change and sustain talk were influenced by coaches' use of MI-consistent and MI-inconsistent language. Consistent with social learning principles and research demonstrating the powerful role of parent positive reinforcement in increasing child self-regulation (Sitnick et al., 2015), teacher sustain talk was more likely to occur following coach use of MI-consistent language and teacher change talk.

\section{Adolescents and Young Adults}

The papers focusing on applying MI methods with adolescents and young adults span the gamut of using MI to enhance engagement in an independent intervention, to developing an MI program for a growing and potentially vulnerable population of 9th graders, and to redesigning the development of a measure that could have relevance for MI approaches. Specifically, Terry et al. (2021) used MI to boost engagement in a modular cognitive-behavior therapy program. Adolescents receiving the MI program showed increases in behavioral and emotional functioning, higher self-efficacy, and expectations to regulate behaviors and succeed at school. Suldo et al. (2021) described the development of a MI intervention for high school freshmen taking accelerated high school curricula (i.e., advanced placement or international baccalaureate classes), with initial results suggesting the program to be highly acceptable to students, interventionists, and school mental health staff. Finally, Lee et al. (2021) described the development of a measure assessing the consequences of marijuana use for young adults. As prior measures of adolescent use of marijuana had been adapted based on the consequences of alcohol use, the new measure, based on consequences of actual young adult marijuana use, should make an important contribution to applications of MI tailored to marijuana abuse.

\section{Conclusion}

In summary, the current Special Issue on advances in the use of MI approaches within the field of prevention science brings together an understandably varied group of papers reflecting the diversity in which MI recently has been applied in innovative ways to multiple age groups, 
vulnerable populations, and modalities. We look forward to MI's continued growth and refinements across these multiple domains in the coming years.

\section{Declarations}

Consent for Publication This commentary was written in compliance with ethical standards of our host institutions, the University of Pittsburgh and University of Virginia, and those of the American Psychological Association.

Conflict of Interest The authors declare no competing interests.

\section{References}

Berkel, C., Mauricio, A. M., Rudo-Stern, J., Dishion, T. J., \& Smith, J. D. (2021). Motivational interviewing and caregiving engagement in the family check-up 4 health. Prevention Science. https://doi. org/10.1007/s11121-020-01112-8

Canfield, C., Miller, E., Shaw, D. S., Morris, P., Roby, E., \& Mendelsohn, A. (2021). Increasing reach of preventive programs through a tiered approach tailored to heterogeneity in risk. Presented at the virtual biennial meeting of the Society for Research in Child Development.

Connell, A. M., McKillop, H. N., \& Dishion, T. J. (2016). Long-term effects of the family check-up in early adolescence on risk of suicide in early adulthood. Suicide and Life Threatening Behavior, 46, S15-S22. https://doi.org/10.1111/sltb.12254

Connell, A. M., Shaw, D. S., Wilson, M. N., Danzo, S., Dishion, T. J., \& Lemery-Chalfant, K. (2019). Indirect effects of the early childhood family check-up on adolescent suicide risk: The mediating role inhibitory control. Development and Psychopathology, 31, 1901-1910. https://doi.org/10.1017/S0954579419000877

Dishion, T. J., Shaw, D. S., Connell, A., Wilson, M. N., Gardner, F., \& Weaver, C. (2008). The family check-up with high-risk families with toddlers: Outcomes on positive parenting and early problem behavior. Child Development, 79, 1395-1414. https://doi.org/10. 1111/j.1467-8624.2008.01195.x

Larson, M., Cook, C. R., Brewer, S. K., Pullmann, M. D., Hamlin, C., Merle, J. L., Duong, M., Gaias, L., Sullivan, M., Morrell, N., Kulkarni, T., Weeks, M., \& Lyon, A. R. (2021). Examining the effects of a brief, group-based motivational implementation strategy on mechanisms of teacher behavior change. Prevention Science. https://doi.org/10.1007/s11121-020-01191-7

Lee, C. M., Kilmer, J. R., Neighbors, C., Cadigan, J. M., Fairlie, A. M., Patrick, M. E., Logan, D. E., Walter, T., \& White, H. R. (2021). A marijuana consequences checklist for young adults with implications for brief motivational intervention research. Prevention Science. https://doi.org/10.1007/s11121-020-01171-x

Miller, W. R., \& Rollnick, S. (2002). Motivational interviewing: Preparing people for change (2nd ed.). Guilford Press.

Owens, J. S., Lee, M., Kassab, H., Evans, S. W., \& Coles, E. C. (2021). Motivational ruler ratings among teachers receiving coaching in classroom management: Measurement and relationship to implementation integrity. Prevention Science. https://doi.org/10.1007/ s11121-020-01111-9

Pas, E., Borden, L., Herman, K., \& Bradshaw, C. P. (2021). Leveraging Motivational Interviewing to coach teachers in the implementation of preventive evidence-based practices: A sequential analysis of the Motivational Interviewing process. Prevention Science. (DOI needed).
Patterson, G.R. (1982). A social learning approach: 3. Coercive family process. Eugene, OR: Castalia.

Pelham, W., Dishion, T. J., Tein, JY, Shaw, D. S., \& Wilson, M. N. (2017). What doesn't work for whom? Predicting responsiveness to the family check-up in early childhood using a mixture model approach. Prevention Science, 18, 911-922. https://doi.org/10. 1007/s11121-017-0805-1

Reinke, W. M., Lewis-Palmer, T., \& Merrell, K. (2008). The classroom check-up: A classwide teacher consultation model for increasing praise and decreasing disruptive behavior. School Psychology Review, 37, 315-332. https://doi.org/10.1080/02796015.2008.12087879

Roby, E., Shaw, D. S., Morris, P., Canfield, C. F., Miller, E. B., Dreyer, B. P., Klas, P. E., Ettinger, A., Miller, E., \& Mendelsohn, A. L. (2021). Pediatric primary care and partnerships across sectors to promote early child development. Academic Pediatrics. https:// doi.org/10.1016/j.acap.2020.12.002

Shaw, D. S., Dishion, T. J., Supplee, L. H., Gardner, F., \& Arnds, K. (2006). Randomized trial of a family-centered approach to the prevention of early conduct problems: 2-year effects of the family check-up in early childhood. Journal of Consulting and Clinical Psychology, 74, 1-9. https://doi.org/10.1037/0022-006x.74.1.1

Shaw, D. S., Forgatch, M. S., Fishbein, D. H., \& Sandler, I. N. (2018). The life and contributions of Thomas Dishion. Prevention Science, 18, 849-852. https://doi.org/10.1007/s11121-018-0934-1

Shaw, D. S., Morris, P. M., \& Mendelsohn, A. L. (under review). The Smart Beginnings model: Tiered prevention integrated in health care and home visiting to address poverty disparities in child development and promote school readiness.

Shelleby, E. C., \& Shaw, D. S. (2014). Outcomes of parenting interventions for child conduct problems: A review of differential effectiveness. Child Psychiatry and Human Development, 45, 628-645. https://doi.org/10.1007/s10578-013-0431-5

Sibley, M. H., Graziano, P. A., Bickman, L., Coxe, S. J., Martin, P., Rodriguez, L. M., Fallah, N., \& Ortiz, M. (2021). Implementing parent-teen motivational interviewing + behavior therapy for ADHD in community mental health. Prevention Science. https:// doi.org/10.1007/s11121-020-01105-7

Sitnick, S. L., Shaw, D. S., Gill, A., Dishion, T., Winter, C., Waller, R., Gardner, F., \& Wilson, M. (2015). Parenting and the family check-up: Changes in observed parent-child interaction following early childhood intervention. Journal of Clinical Child and Adolescent Psychology, 44, 970-984. https://doi.org/10.1080/15374416.2014.940623

Small, J. W., Frey, A., Lee, J., Seeley, J. R., Scott, T. M., \& Sibley, M. H. (2021). Fidelity of Motivational Interviewing in school-based intervention and research. Prevention Science. https://doi.org/10.1007/ s11121-020-01167-7

Stormshak, E. A., DeGarmo, D., Garbacz, S. A., McIntyre, L. L., \& Caruthers, A. (2021). Using Motivational Interviewing to improve parenting skills and prevent problem behavior during the transition to kindergarten. Prevention Science. https://doi.org/10.1007/ s11121-020-01102-w

Stormshak, E. A., Seeley, J. R., Caruthers, A. S., Cardenas, L., Moore, K. J., Tyler, M. S. Fleming, C. M., Gau, J., \& Danaher, B. (2019). Evaluating the efficacy of the family check-up online: A schoolbased eHealth model for the prevention of problem behavior during the middle school years. Development and Psychopathology, 31, 1873-1886. https://doi.org/10.1017/S0954579419000907

Suldo, S. M., Wang, J. H., O’Brennan, L. M., Shaunessy-Dedrick, E., Dedrick, R. F., DiLeo, L. L., Ferron, J. M., \& Lee, J. (2021). A motivational interviewing intervention for adolescents in accelerated high school curricula: Applicability and acceptability in a second sample. Prevention Science. https://doi.org/10.1007/s11121-020-01204-z

Terry, J. D., Weist, M. D., Strait, G. G., \& Miller, M. (2021). Motivational Interviewing to promote the effectiveness of selective prevention: An integrated school-based approach. Prevention Science. https://doi.org/10.1007/s11121-020-01124-4 
Thompson, A. M., Widermann, W., Herman, K. C., \& Reinke, W. M. (2021). Effect of daily teacher feedback on subsequent motivation and mental health outcomes in fifth grade students: A personcentered analysis. Prevention Science. https://doi.org/10.1007/ s11121-020-01097-4
Publisher's Note Springer Nature remains neutral with regard to jurisdictional claims in published maps and institutional affiliations. 